\title{
Desenvolvimento de Aplicativos Móveis por Meninas: Uma Abordagem Participativa
}

\section{Cristiane Jorge de Lima Bonfim ${ }^{1}$, Alane Beatriz da Nóbrega Martins ${ }^{1}$, Jaline Gonçalves Mombach ${ }^{1}$, Janara Kalline Leal Lopes de Sousa ${ }^{2}$}

\author{
${ }^{1}$ Instituto de Educação, Ciência e Tecnologia de Brasília - Campus Brasília \\ Setor de Grandes Áreas Norte 610 - Asa Norte - 70830-450 - Brasília - DF - Brasil \\ ${ }^{2}$ Faculdade de Comunicação - Universidade de Brasília (UnB) \\ Campus Darcy Ribeiro - ICC Norte Asa Norte - 70 910-900 - Brasília - DF - Brasil \\ \{cristiane.bonfim, jaline.mombach\}eifb.edu.br \\ \{alane.nm, janara.sousa\}@gmail.com
}

\begin{abstract}
The incentive of girls to technology has been the subject of several studies. One way to enable them to interact more effectively with the area is through Participatory Design. Thus, this article aims to present a teaching experience of programming mobile applications for girls, using activities of Participatory Design for empowerment and digital inclusion. The methodology involves moments of planning, interface design, programming, and documentation, seeking to approach the real environment of development. After the meetings, the girls answered a questionnaire, and the answers allow us to observe that the majority of participants indicate an increase in interest in technology after the experience.
\end{abstract}

Resumo. O incentivo de meninas à tecnologia tem sido tema de diversos estudos. Uma forma de possibilitar que elas interajam mais efetivamente com a área é por meio do Design Participativo. Assim, este artigo tem como objetivo apresentar uma experiência de ensino de programação de aplicativos móveis para meninas, usando atividades de Design Participativo para empoderamento e inclusão digital. A metodologia envolve momentos de planejamento, design de telas, programação e documentação, buscando aproximar-se do ambiente real de desenvolvimento. Após os encontros, as meninas responderam a um questionário, e as respostas nos permitem observar que a maioria das participantes indica um aumento no interesse pela tecnologia após a experiência.

\section{Introdução}

Pesquisas mostram que a participação feminina na área de tecnologia é menor quando comparada à representação masculina [Lima 2013]. Por isso, estudos estão sendo realizados para analisar o cenário e possível mudança para inclusão de mais mulheres atuantes na Tecnologia da Informação (TI) ${ }^{1}$. Uma pesquisa da Microsoft em 12 países da Europa,

\footnotetext{
1 "Como exemplos, pode-se citar o programa governamental Mulher e Ciência (CNPQ, 2013), e o Made With Code (GOOGLE, 2015), promovido pelo Google. Outro indicador da relevância do tema foi sua inclusão entre os oito desafios de desenvolvimento do milênio lançados pelas Nações Unidas: 'Promover a igualdade de gênero e a autonomia das mulheres"'.[Dantas et al. 2017]
} 
VII Congresso Brasileiro de Informática na Educação (CBIE 2018)

Anais dos Workshops do VII Congresso Brasileiro de Informática na Educação (WCBIE 2018)

perguntou a 11.500 mulheres entre 11 e 30 anos de idade sobre suas atitudes em relação ao Ensino de ciências, tecnologia, engenharia e matemática na escola. A pesquisa mostrou que a maioria das meninas têm interesse por tecnologia aos 11 anos de idade, mas aos 15 anos já não se sentem mais atraídas. Os motivos comentados por elas trata sobre a falta de modelos femininos na área, o desconhecimento prático e o receio de homens e mulheres não terem tratamento igualitário nas profissões de TI [Microsoft Corporation 2017].

O contexto brasileiro que desestimula a participação feminina nas áreas tecnológicas encontra raízes culturais. Desde o Brasil colônia, as raízes profundas da dominação masculina [Bourdieu 1996] marcam profundamente a cultura brasileira reservando à mulher um papel de submissão com relação ao masculino e lhe reservando menos espaço tanto no ambiente profissional, quanto nos ambientes de tomada de decisões de poder. Como evidência, é emblemático que o congresso brasileiro tenha pouco mais de 10 por cento de representação feminina [IBGE 2018]. Alijadas dos espaços de poder o feminino é percebido como o antagônico ao masculino, ou seja mole, fraco, insolvente financeiramente e dependente [Bourdieu 1996]. Logo, a educação das mulheres brasileiras é marcada por esse contexto e nesse processo a proximidade com a tecnologia é normalmente destinada ao homem, visto como mais apto à lidar com o tema, enquanto que as mulheres são estimuladas a se dedicarem às áreas de Ciências Sociais e Humanas.

Dessa maneira, acredita-se que incluir meninas em atividades que visam maior interação com a área possa despertar o interesse por conhecimentos em TI. Uma abordagem que está diretamente ligada ao envolvimento ativo de usuários finais é o Design Participativo (DP). O surgimento dessa metodologia deu-se há praticamente meio século, considerando sua origem em território escandinavo entre os anos 70 e 80, com o objetivo de "capacitar trabalhadores e promover a democracia no local de trabalho" [Spinuzzi 2005]

Nesta direção, o presente artigo tem como objetivo apresentar uma experiência de ensino de programação de aplicativos móveis para meninas, usando atividades de DP para empoderamento e inclusão digital. O presente trabalho envolveu a participação de meninas, com idades entre 14 e 19 anos, estudantes da educação básica do Distrito Federal. Além de fortalecer a inclusão digital e o DP, o projeto visou a construção de aplicativos móveis como proposta de combate a diferentes tipos de violência de gênero e de raça, praticadas principalmente em ambientes virtuais. Os Aplicativos desenvolvidos foram propostos pelas próprias estudantes, tendo o auxílio de professoras e estudantes de TI e de outros cursos relacionados à temática.

O presente artigo está organizado em cinco Seções: a Seção 2 apresenta os trabalhos relacionados ao tema DP em contextos e recortes diferentes. A Seção 3 aborda a Metodologia Participativa e seus conceitos teórico-metodológicos norteadores da experiência de programação de aplicativos por usuárias finais, a Seção 4 apresenta os resultados preliminares e a Seção 5 as considerações finais.

\section{Design Participativo para Empoderar}

Conforme dito no tópico anterior, no Brasil ainda vivemos sob a égide da dominação masculina. No entanto, é preciso marcar que houve e há movimentos de resistência que têm alçado grandes conquistas no sentido de garantir uma equidade de gênero. Neste contexto, desde a década de 1970 erigiu, no seio dos movimentos da sociedade civil, a ideia da necessidade do empoderamento da mulher para que ela seja capaz de sair do sis- 
tema de opressão masculina. O empoderamento feminino é, portanto, fundamentalmente ligado ao desenvolvimento de uma equidade de gênero e à capacidade de luta e resistência da mulher contra a ordem estabelecida [Foucault 1985]. Logo, a proposta de investir no estímulo ao empoderamento desde a infância e adolescência é seminal para a construção de novos valores na sociedade.

Os conceitos estabelecidos pela Engenharia de Software abordam etapas sequenciais e pré-estabelecidas para o desenvolvimento de um sistema, seja ele para Desktop, Web ou Aplicativo. As fases se resumem em levantamento de requisitos do sistema, análise, prototipagem, testes e entrega [Pressman and Maxim 2016]. O desenvolvimento de um sistema demanda uma equipe especializada que utiliza os requisitos do sistema fornecidos pelos usuários demandantes do mesmo e estes mesmos usuários participam, em geral, da aprovação do protótipo e da fase de testes.

O modelo citado é utilizado em todo o mundo por empresas desenvolvedoras de Sistemas, porém estudos recentes mostram que os usuários podem participar de forma ativa na etapa de fornecimento dos requisitos do sistema que definirá suas funcionalidades, e ainda participar das decisões do design, conforme suas necessidades, do ponto de vista das funcionalidades e usabilidade. Essa abordagem é crescente, considerando que de um lado, o não-designer busca satisfação, enquanto que do outro, o designer procura assertividade [Silva 2012]. Neste sentido, entende-se que os ganhos podem ser mútuos, se houver uso do DP na construção de qualquer tecnologia, tendo em mente a sua aplicação em diversas áreas.

Uma das abordagens do DP é procurar compreender as demandas dos usuários através de suas percepções e sensações [Costa and Souza 2017]. Dessa forma, no contexto desse trabalho, levando em consideração a temática de combate à violência de gênero, de raça e cyberbullying nas redes sociais, destaca-se a importância da atuação feminina na construção de aplicativos, isso porque somente a partir de suas opiniões e vivências é que soluções próximas de suas realidades poderão ser pensadas neste processo. Além disso, mais do que possibilitar a concretização de suas ideias, incentiva-se a participação nos processos de decisão, uma vez que o espaço colaborativo é horizontal, o que reforça a autonomia das estudantes, além de estimular o interesse pela área de TI, corroborando também aos propósitos éticos do DP de empoderamento e de justiça social de gênero, como já apontados por [Falcão et al. 2017].

O espaço de fala presente nesta experiência é importante não apenas no contexto escolar, mas como valor emocional, uma vez que a horizontalidade nas relações de poder é essencial entre as envolvidas no projeto, motivando as adolescentes no engajamento e na participação em processos de DP [Falcão et al. 2017]. Por consequência, além de estimular a inserção feminina na área de TI, o projeto buscou o pleno envolvimento das estudantes na concepção de aplicativos que considerassem suas experiências e suas expectativas de combate à violência de gênero, de raça e de cyberbullying propiciando-lhes uma forma de inclusão digital, a partir da introdução à programação, utilizando-se a ferramenta App Inventor. Esses aspectos estão fortemente relacionados aos princípios democráticos, emancipadores, éticos e educacionais do DP.

Na próxima Seção é apresentada a metodologia participativa adotada, na qual a participação das meninas não foi apenas como meras expectadoras, mas como idealiza- 
VII Congresso Brasileiro de Informática na Educação (CBIE 2018)

Anais dos Workshops do VII Congresso Brasileiro de Informática na Educação (WCBIE 2018)

doras, designers e programadoras, atuantes em todas as dimensões do desenvolvimento do aplicativo.

\section{Materiais e Métodos}

Nesta Seção apresentam-se os principais conceitos teórico-metodológicos que norteiam a ação, bem como a contextualização sobre o projeto em que as práticas de programação descritas estão incluídas. A metodologia de DP permite a participação do usuário no processo de criação do design do produto, no caso específico deste artigo apresentamos a metodologia aplicada à criação aplicativos móveis por meio da ferramenta MIT App Inventor, envolvendo meninas estudantes do ensino médio. ${ }^{2}$

\subsection{O projeto}

O projeto ${ }^{3}$, desenvolvido no âmbito do grupo de pesquisa Internet e Direitos Humanos, que integra o Laboratório de Políticas de Comunicação (Lapcom) da Faculdade de Comunicação da Universidade de Brasília (UnB), em parceria com o Laboratório de Tecnologias Educacionais do Instituto Federal de Brasília (IFB) Campus Brasília, tem o objetivo de compreender a violência online de gênero, apontando suas características, sua recorrência, sua tipologia, bem como as consequências para as vítimas, propondo ações de enfrentamento interinstitucional no âmbito das escolas públicas de ensino médio e servindo de subsídio para a criação da Rede Nacional de Proteção às Mulheres e Meninas na Internet. O projeto Escola de App, é desenvolvido em sete etapas conforme segue: Pesquisa Bibliográfica e Documental (1), Entrevistas com Professores e Diretores (2), Grupos Focais com Meninas (3), Treinamento das Meninas para Desenvolvimento de Aplicativos (4), Palestras para Professores (5), Lançamento do Site de Direitos Virtuais das Meninas (6) e Dossiê para Criação da Rede Nacional de Proteção às Mulheres na Internet(7).

Este artigo limita-se ao relato da experiência obtida na etapa quatro do projeto que tem foco no treinamento das meninas para criação e desenvolvimento de aplicativos móveis.

\subsection{Abordagem Participativa com Meninas}

A criação dos aplicativos foi guiada pelos princípios do DP, unindo às etapas de desenvolvimento que são comuns ao ambiente real: planejamento, design de telas, programação e documentação.

A metodologia utilizada é apresentada na figura 1 e está organizada em 4 blocos de atividades que se interligam sequencialmente do ponto de vista da construção do App e finaliza com a avaliação da metodologia como um todo. No primeiro bloco foram utilizadas as três técnicas: Brainstorming, Paper Prototype e Pitch Elevator. Esta sequência de técnicas tem como objetivo possibilitar que projeto do App esteja pronto em três horas já no primeiro encontro, proporcionando um sentimento de pertença e empoderamento gradual no contexto da tecnologia, que atinge seu ápice ao final do $3^{\circ}$ bloco.

O primeiro bloco inicia com a técnica de Brainstorming e foi organizado em dois momentos, o primeiro durou aproximadamente 30 minutos com objetivo de instigar a

\footnotetext{
${ }^{2}$ Disponível em: http://appinventor.mit.edu/explore/

${ }^{3}$ Projeto Escola de app. Disponível em: ¡https://www.internetedireitoshumanos.com.br/publicacoes $\underset{j}{ }$. Acesso em: 12 jun 2018.
} 
VII Congresso Brasileiro de Informática na Educação (CBIE 2018)

Anais dos Workshops do VII Congresso Brasileiro de Informática na Educação (WCBIE 2018)

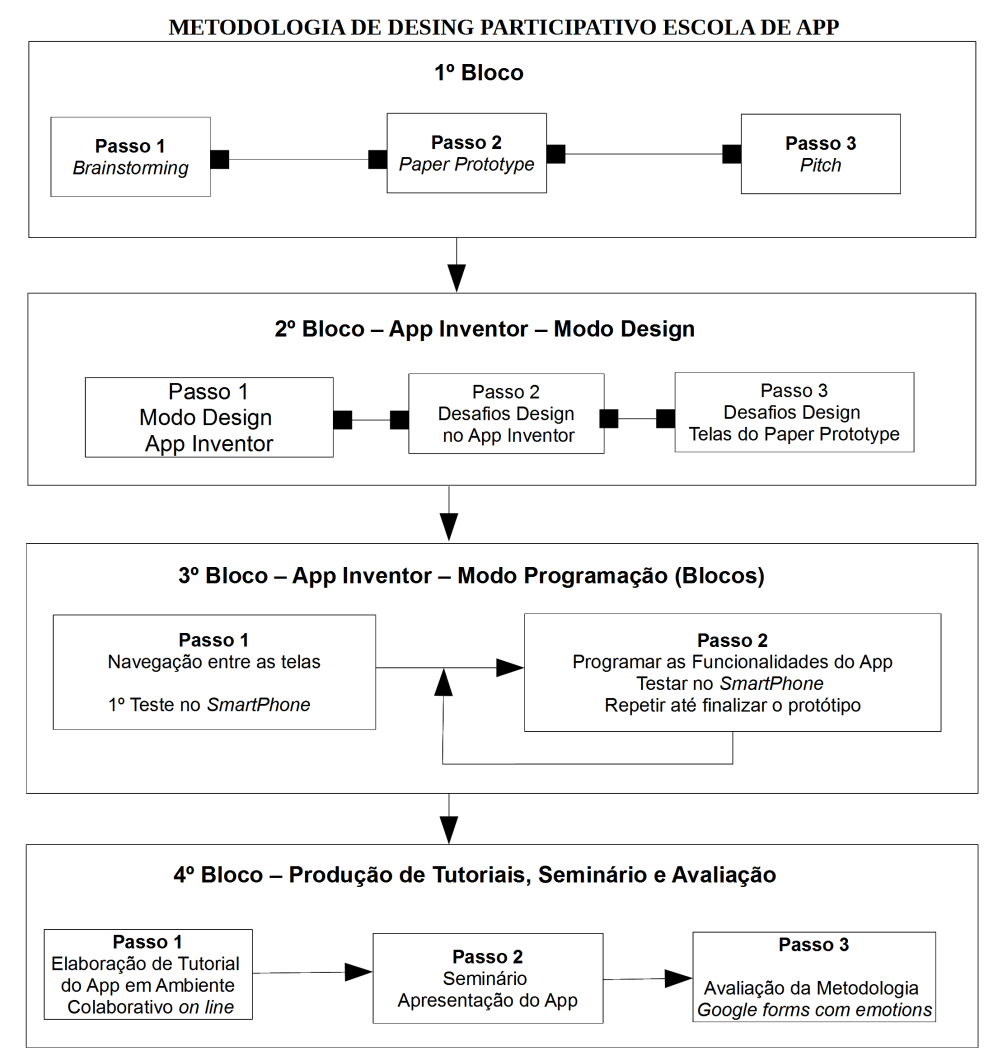

Figura 1. Metodologia Design Participativo do Projeto

criatividade das participantes, com apresentação de aplicativos sobre a temática de gênero e raça já existentes e App criados por meninas. No segundo momento as duplas ficaram livres para pensar, debater e propor o App. No segundo passo foi usada a técnica Paper Prototype que é a montagem dos protótipos em papel. Esta construção utilizou cartolina, tesoura, caneta e cordão colorido. Os aplicativos propostos tem a tela de entrada e outras telas que são acessadas a partir da primeira e que disponibilizam algumas funcionalidades que permitem acesso a vídeos no Youtube ou à sítios que possibilitem alguma interação como blogs e Facebook. A Figura 2 apresenta um mockup criado e uma das duplas durante a técnica de Paper Prototype.

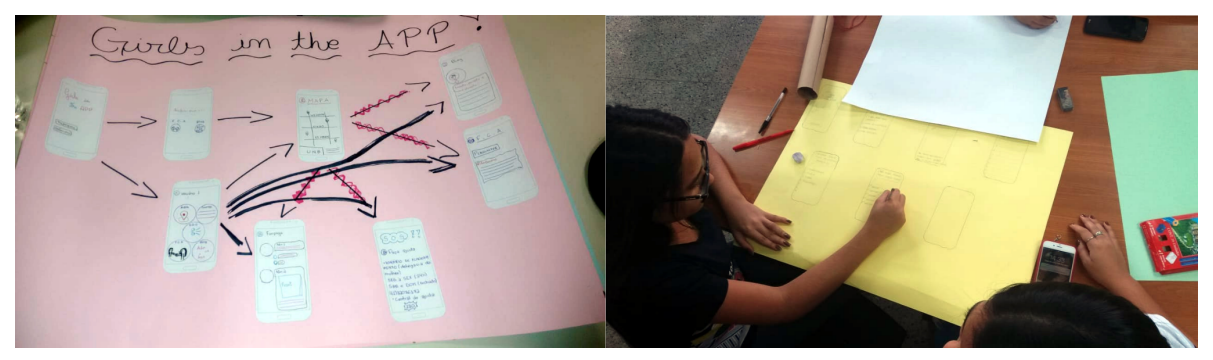

Figura 2. Criação dos mockups para os aplicativos

Após a finalização das criações dos Mockups, as meninas foram convidadas a fazer uma apresentação em adaptação livre à técnica Pitch Elevator [Spina 2012] ${ }^{4}$, que

\footnotetext{
${ }^{4}$ Esta técnica é muito utilizada por empreendedores para apresentação de projetos para investidores.
} 
VII Congresso Brasileiro de Informática na Educação (CBIE 2018)

Anais dos Workshops do VII Congresso Brasileiro de Informática na Educação (WCBIE 2018)

consiste em uma uma apresentação curta de 3 a 5 minutos que permita apresentar o projeto do app: objetivos, público-alvo, tipo de conteúdo e funcionalidades gerais. Essa técnica foi utilizada no contexto da metodologia de DP para que houvesse a possibilidade das participantes apresentarem seus projetos, receberem sugestões das outras participantes e da equipe ministrante, para melhorar as propostas dos aplicativos ainda nesta fase de projeto. A equipe ministrante observou que a maioria das participantes teve boa desenvoltura, apresentando com propriedade intelectual o seu projeto, mesmo diante da limitação do tempo e necessidade de síntese. Assim, o objetivo do uso da ferramenta foi alcançado. As apresentações dos pitches foram filmadas e fazem parte do acervo do projeto. No segundo bloco iniciamos o Modo Design. O passo 1 inclui a configuração do ambiente de programação utilizado que é o MIT App Inventor, em seguida é criado o projeto do aplicativo pelas participantes, e ao final do bloco são apresentados os desafios, conforme ilustra a Figura ??app inventorfig:Desafios app inventor.

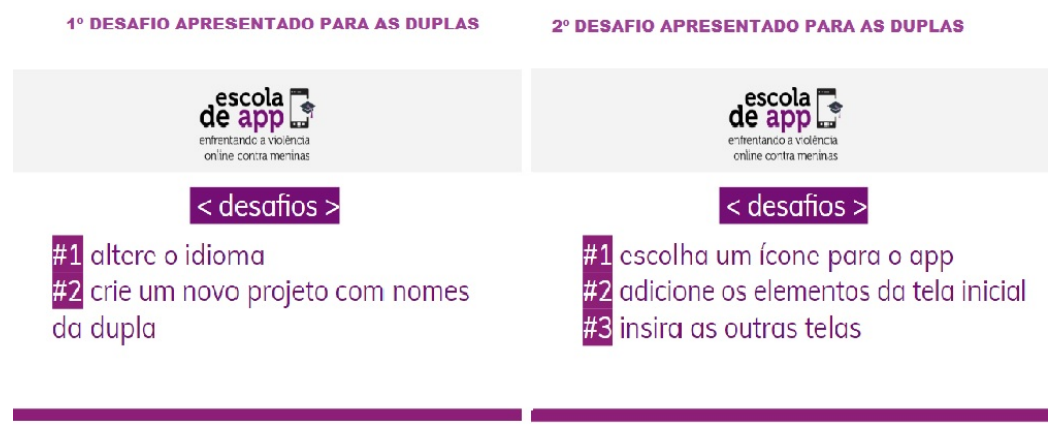

Figura 3. Desafios App Inventor

A criação do Design bem como a escolha do ícone do App, é feito neste segundo bloco denominado Modo Design, para este fim, foram utilizadas os bancos com imagens vetoriais gratuitas como FlatIcon ${ }^{5}$, FreePik ${ }^{6}$ e Icons $8^{7}$. Tomadas as decisões do ponto de vista da criação dos ícones e feito o upload para a plataforma App Inventor, o trabalho se debruça em adicionar os elementos da tela inicial utilizando a consulta do Mockup até a finalização do protótipo na plataforma. A partir da primeira tela, segue a criação e desenvolvimento do design das demais telas de acordo com o mockup criado na fase de Paper Prototype. Foram trabalhados os conceitos de propriedade intelectual e a dimensão ética do uso de textos de imagens na internet sem autorização, assim, foram utilizados os sítios com imagens creative commons para uso no design nos Apps já mencionados.

O terceiro bloco totalmente dedicado a programação se desenvolveu a partir do passo 1 feita a implementação Botões de navegação entre as telas e instalação no smartphone para o primeiro teste. Cabe um destaque a este momento no qual as participantes se veem capazes de programar seu próprio App e é notório o empoderamento e o entusiasmo em aprofundar os conhecimentos sobre a ferramenta App Inventor para terminar o App. O passo 2 tem foco na implementação das funcionalidades de cada App que vai sendo testado a cada novo item implementado. As funcionalidades mais utiliza-

\footnotetext{
Disponível em: https://endeavor.org.br/dinheiro/como-elaborar-um-pitch-quase-perfeito

${ }^{5}$ Disponível em https://www.flaticon.com/

${ }^{6}$ Disponível em https://br.freepik.com/

${ }^{7}$ Disponível em https://icons8.com.br/
} 
VII Congresso Brasileiro de Informática na Educação (CBIE 2018)

Anais dos Workshops do VII Congresso Brasileiro de Informática na Educação (WCBIE 2018)

das nos App foram, links para sítios de internet que em geral trazem mais informações ou possibilidades de interação com outras pessoas que estão discutindo o mesmo tema. Também usados links para vídeos do Youtube. Cabe destacar que alguns Apps utilizaram o recursos do Hardware dos Smartphones tais como: sensores de acelerômetro e de proximidade, entre outras funcionalidades como acesso à agenda para discagem de chamada de socorro, ou para números pré-definidos na programação para Centro de Valorização da Vida (Disque 188) ou Central de Atendimento à Mulher (Disque 180). Ao final do desenvolvimento do aplicativo as participantes elaboraram um tutorial conforme Figura 4. a partir do modelo disponibilizado no ambiente do Google Drive online, permitindo o trabalho cooperativo e colaborativo. Foi criado um tutorial para cada App contendo: nome do aplicativo e das autoras, seu objetivo e como usar as telas, botões e funcionalidades disponíveis.

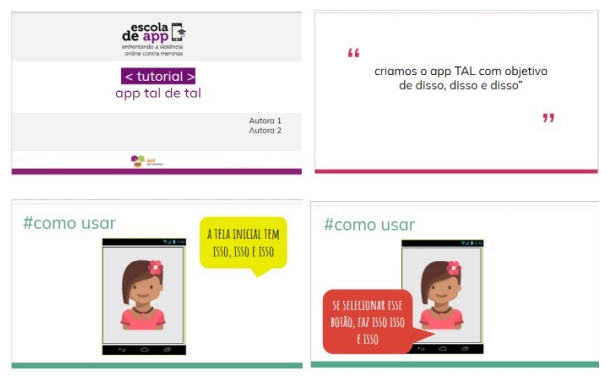

Figura 4. Modelo do Tutorial

Foram utilizadas as respectivas telas para ilustrar melhor a usabilidade do App. O objetivo da criação do tutorial é "documentar" o aplicativo criado e disponibilizar o conteúdo na galeria de apps do MIT App Inventor. Também, criamos um questionário para avaliação da proposta pelas adolescentes, adotando uso de emoticons e linguagem menos formal adaptado à faixa-etária, conforme exemplificado na Figura 5.

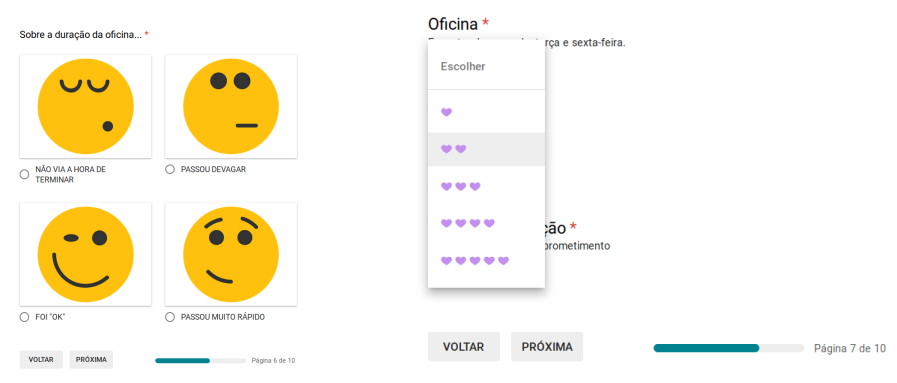

Figura 5. Exemplos de questões apresentadas na avaliação

Por fim, as meninas são convidadas para um roda de conversa em que apresentam os produtos criados (aplicativos) a todas as demais participantes, explicando os principais desafios e opinando sobre a experiência obtida. A próxima Seção relata os resultados preliminares obtidos após a aplicação dessa metodologia em duas escolas.

\section{Resultados Preliminares}

A experiência foi aplicada em duas escolas da rede distrital do Distrito Federal, em grupos com 19 meninas em cada, com idades entre 14 e 19 anos, todas alunas do Ensino 
VII Congresso Brasileiro de Informática na Educação (CBIE 2018)

Anais dos Workshops do VII Congresso Brasileiro de Informática na Educação (WCBIE 2018)

Médio. No total, foram criados 16 aplicativos pelas participantes com subtemas escolhidos por elas, conforme descrição da Tabela 1. A relação entre categoria e quantidade é apresentada no gráfico da Figura 6.

Tabela 1. Categorias de Aplicativos Criados no Projeto

\begin{tabular}{|l|l|}
\hline Categoria do App & Descrição \\
\hline $\begin{array}{l}\text { Empoderamento } \\
\text { Feminino }\end{array}$ & Disponibilizam informações para empoderar a mulher \\
\hline Raça e Gênero & Aborda temas relacionados com a mulher negra \\
\hline $\begin{array}{l}\text { Violência Contra a } \\
\text { Mulher }\end{array}$ & $\begin{array}{l}\text { Traz o tema no sentido de conscientizar a mulher para identificar se ela está em } \\
\text { relacionamento abusivo e indica caminhos para se apoiar e sair da situação }\end{array}$ \\
\hline $\begin{array}{l}\text { Empoderamento } \\
\text { LGBT }\end{array}$ & $\begin{array}{l}\text { Propõe o respeito à liberdade de gênero e o empoderamento para conquistar } \\
\text { seu espaço na sociedade }\end{array}$ \\
\hline $\begin{array}{l}\text { Violência contra as } \\
\text { Minorias }\end{array}$ & Discute a violências contra as minorias muitas vezes velada na sociedade \\
\hline $\begin{array}{l}\text { Prevenção } \\
\text { Suicídio do }\end{array}$ & $\begin{array}{l}\text { Traz frases de esperança e razões para viver. Faz ligação para o CVV e tem } \\
\text { links para sites de ajuda online }\end{array}$ \\
\hline
\end{tabular}

Os Apps mantiveram coerência com os temas abordados pela fase conceitual do projeto. O gráfico da figura 6 mostra o total de App por categoria.

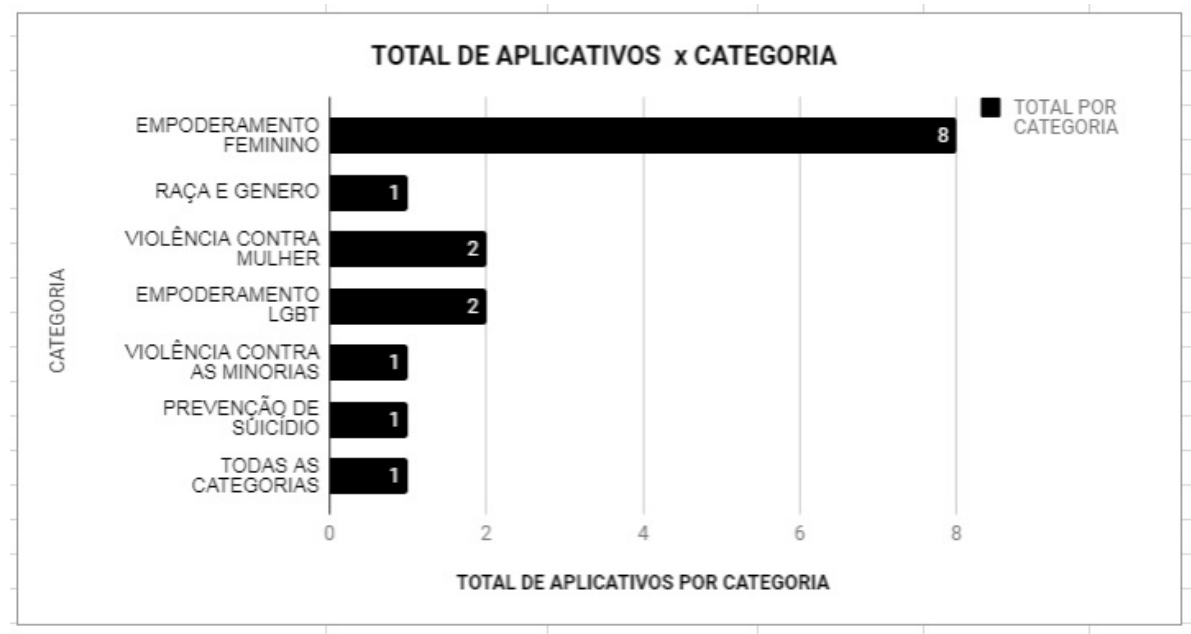

Figura 6. Quantidade de aplicativos criados por categoria

Pode-se constatar que todas as categorias tiveram pelo menos um App, sendo importante destacar que dos aplicativos desenvolvidos, um se destaca por abordar todas as categorias, embora tenha ficado com um número grande de telas. Vale ressaltar que $50 \%$ dos aplicativos foram classificados na categoria Empoderamento Feminino, o que demonstra que um dos temas centrais da etapa conceitual do projeto tem aderência ao interesse das participantes. A Figura ??AppCED104fig:TelasAppCED104 exibe exemplos de telas dos aplicativos criados pelas meninas. Das 38 meninas participantes, 29 responderam o questionário que ficou disponível por 7 dias, após a finalização dos encontros.

A primeira pergunta, "O que te motivou a fazer o App?" teve como maioria das respostas a possibilidade de ajudar outras meninas e mulheres, como "ver que muitas 
VII Congresso Brasileiro de Informática na Educação (CBIE 2018)

Anais dos Workshops do VII Congresso Brasileiro de Informática na Educação (WCBIE 2018)

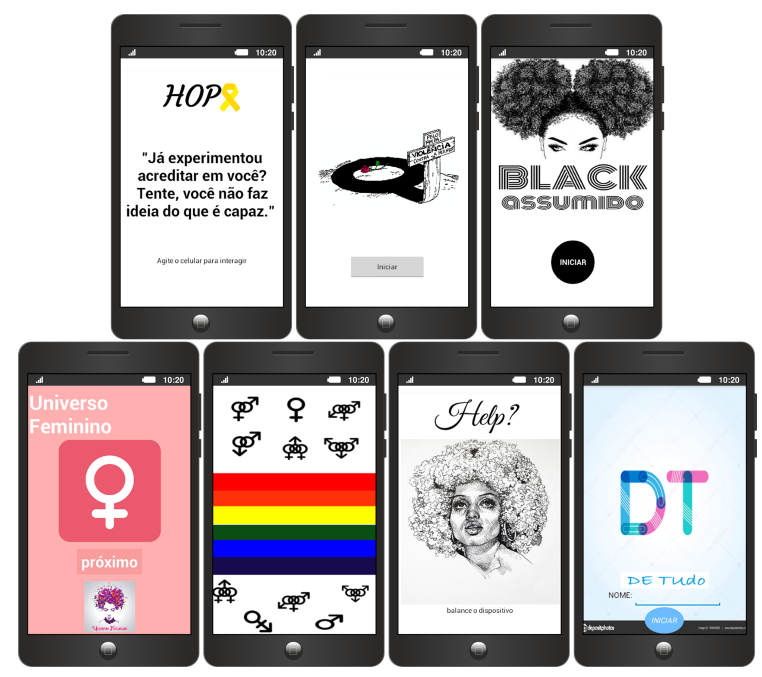

Figura 7. Telas de alguns aplicativos criados

meninas sofrem e às vezes não tem ninguém para desabafar" e "ver que muitas meninas não se aceita por o modelo do seu cabelo". As próximas questões tiveram como objetivo identificar se o interesse pela área tecnológica havia mudado após a experiência e os gráficos são apresentados na Figura 8 . O gráfico da figura 8 mostra que após as atividades, apenas uma menina indicou continuar com nenhum interesse pela área, mas as opções "interesse"moderado e "muito grande"passaram a ter maior representatividade, sendo 9 $(31 \%)$ e $19(65,5 \%)$, respectivamente.
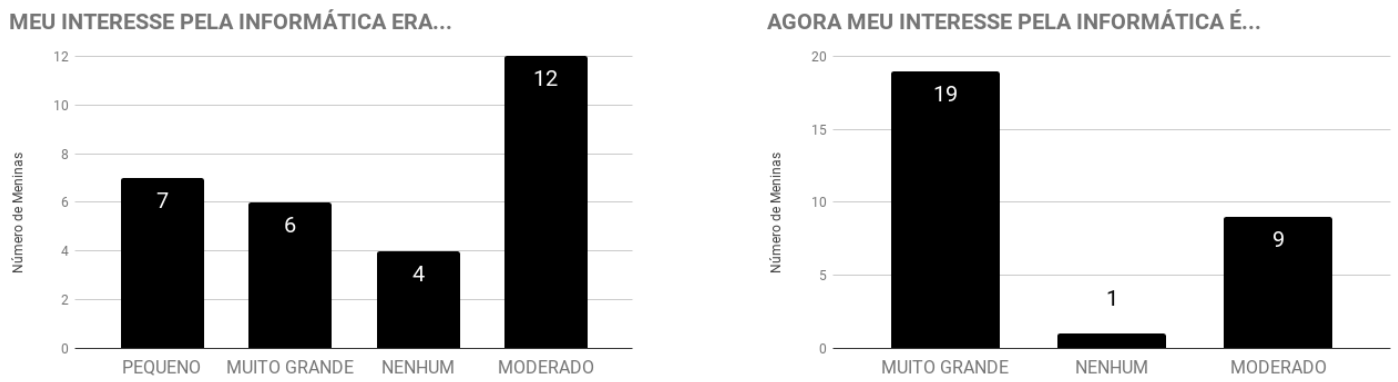

Figura 8. Interesse pela Área de Informática

Percebe-se portanto um notório crescimento no interesse das meninas pela área de Informática. Outras questões diziam respeito à avaliação da ferramenta MIT App Inventor, a autoavaliação e avaliação da equipe executora.

Percebe-se que o DP promoveu às participantes um sentimento de pertença do App desenvolvido, quando nas apresentações, ao final da etapa, elas se referem ao "Nosso aplicativo faz...". Promoveu também, o empoderamento a partir da percepção de que elas têm a capacidade de pensar e propor projetos e programar soluções, trabalhando em grupo na definição de objetivos, possuem a habilidade de criar o design, definir o tema, elaborar os textos e selecionar os sítios para os quais o app abre uma janela para o mundo virtual. 
VII Congresso Brasileiro de Informática na Educação (CBIE 2018)

Anais dos Workshops do VII Congresso Brasileiro de Informática na Educação (WCBIE 2018)

\section{Considerações Finais}

A programação de aplicativos por usuárias finais, utilizando DP, mostrou que o desenvolvimento é centrado na experiência das usuárias desenvolvedoras e expressa seu olhar específico, mas que explora as questões conceituais do projeto que discutiu a violência de gênero, raça e cyberbullying nas redes sociais. A experiência nas duas escolas apresentadas mostrou que foi possível às nossas participantes, pensar e propor um App mais adequado à forma de pensar e de interagir de cada uma, assim a metodologia possibilitou às participantes a criação do design de telas, a implementação do App no App Inventor e a elaboração de tutoriais para apresentação em seminários e outros eventos, podendo demonstrar os Apps já instalados em seus smartphones. Os seminários do quarto bloco mostraram um empoderamento mediado pela tecnologia possibilitado pela Metodologia de DP proposto e executado no desenvolvimento do projeto. Salientamos a importância de se oferecer atividades de envolvimento prático com TI para meninas, a fim de estimular maior interesse delas pela área.

\section{Referências}

Bourdieu, P. (1996). A dominação masculina. Rio de Janeiro: Bertrand Brasil.

Costa, D. L. V. and Souza, F. d. F. d. (2017). Desenvolvimento participativo de aplicativos para pessoa com paralisia cerebral utilizaando método dapda. In Anais dos Workshops do Congresso Brasileiro de Informática na Educação, volume 6, page 1384.

Dantas, V. F., de Figueiredo, R. V., Nascimento, R. R., and da Costa, T. L. S. (2017). It girls: Promovendo a igualdade de gênero em tecnologia da informação no litoral norte da paraíba. Anais do Computer on the Beach, pages 463-465.

Falcão, T. P., Oliveira, G. d. S., Peres, F. M. d., and Morais, D. C. S. d. (2017). Design participativo de jogos educacionais na comunidade de prática do projeto demults. In Anais dos Workshops do Congresso Brasileiro de Informática na Educação, volume 6, page 1344.

Foucault, M. (1985). Microfísica do poder. Rio de Janeiro: Graal.

IBGE (2018). Estatísticas de gênero : indicadores sociais das mulheres no Brasil. Rio de Janeiro: IBGE, Coordenação de População e Indicadores Sociais.

Lima, M. P. (2013). As mulheres na ciência da computação. Estudos feministas, pages 793-816.

Microsoft Corporation (2017). Why europe's girls aren't studying stem.

Pressman, R. and Maxim, B. (2016). Engenharia de Software. $8^{a}$ Edição. Rio de Janeiro: McGraw Hill Brasil.

Silva, N. A. N. d. (2012). Abordagens participativas para o design: Metodologias e plataformas sociotécnicas como suporte ao design interdisciplinar e aberto a participação. Master's thesis, Pontifícia Universidade Católica de São Paulo.

Spina, C. A. (2012). Como elaborar um pitch (quase) perfeito. Disponível em: https://endeavor.org.br/como-elaborar-um-pitch-quase-perfeito/. Acesso em: 20 set. 2018.

Spinuzzi, C. (2005). The methodology of participatory design. Technical communication, 52(2):163-174. 